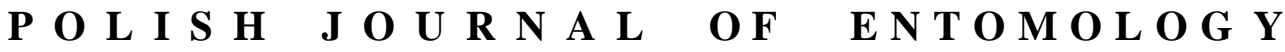

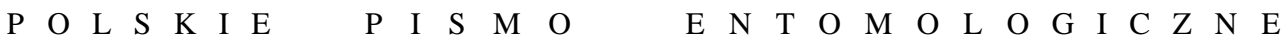

VOL. 84: $155-162$

Lublin

30 September 2015

DOI: $10.1515 /$ pjen-2015-0013

\section{Description of pupal instars of Kermes quercus (LINNAEUS, 1758) (Hemiptera: Kermesidae)}

\author{
ELŻBIETA PODSIADŁO \\ Department of Zoology, Warsaw University of Life Sciences SGGW, Ciszewskiego 8, \\ 02-786 Warsaw, Poland, e-mail: elzbieta_podsiadlo@sggw.pl
}

\begin{abstract}
The third instar male (prepupa) and fourth instar male (pupa) of Kermes quercus are described and illustrated, with the differences between them being indicated. The prepupa has a broadly oval, membranous body, with indistinct segmentation, 9-segmented antennae, 3 -segmented legs, anterior wing-buds extending to about the base of the metathoracic legs, and a broadly rounded medial penial lobe. The pupa has an elongate oval body, with more distinct segmentation and more strongly developed appendages: 10-segmented antennae, 5-segmented legs, wing-buds extending laterally past the coxa of the metathoracic legs, and a long, triangular penial lobe.
\end{abstract}

KEY WORDS: Hemiptera, Kermesidae, Kermes quercus, morphology, third instar male (prepupa), fourth instar male (pupa).

\section{INTRODUCTION}

Kermes quercus (LINNAEUS, 1758) is widely distributed in Europe, commonly found on oaks Quercus spp. The identification of this species in all its life stages is the basis for further studies on various aspects of its biology. Based on the material collected in Poland, the adult male was the first to be described (KOTEJA \& ŻAK-OGAZA 1972), and nymphal instars and adult female in recent years (PODSIADŁO 2005a, 2005b, 2012a, 2012b, 2014). The pupal instars, i.e. prepupa and pupa, have not been described from Poland or from other European countries. The general appearance of these stages from the St. Petersburg (Russia) region was given by NASONOV (1910) and SAAKYAN-BARANOVA \& MUZAFAROV (1972) but without microscopic characters. The present paper fills this information gap. 
Studies of the life history of $K$. quercus in Poland were conducted by PoDSIADŁO (2013). They showed that in the climatic conditions of Poland, K. quercus is not a univoltine species: each generation develops over two years, and so each life stage appears every two years. Pupal stages occur mainly in the April of even-numbered years.

\section{MATERIAL AND METHODS}

The material for this study was collected from Quercus robur LinNAEUS, 1753 in Warsaw. A sample of 16 prepupae was taken on 13 April 2010, and samples of pupae were obtained on 22 April 2010 (11 inds.), 4 May 2010 (2 inds.) and 26 April 2012 (4 inds.). Live specimens were examined under a stereomicroscope and then mounted on slides. The measurements in millimetres $(\mathrm{mm})$ or micrometres $(\mu \mathrm{m})$ are given as averages; the ranges are in parentheses. The numbers of setae are given for one body half.

\section{DESCRIPTION}

Both the third instar male (prepupa) and the fourth instar male (pupa) are enclosed within a white, waxy test 1.9-2.1 mm long and 0.8-1.0 mm wide, produced by the second instar male (Fig. 1).

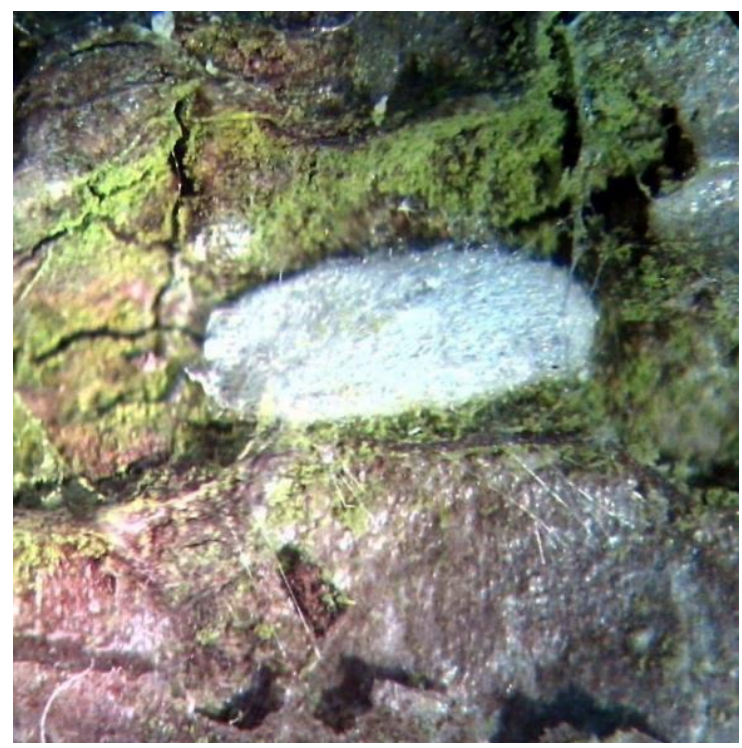

Fig. 1. Male test of Kermes quercus. 


\section{Third instar male (prepupa)}

(Fig. 2)

General appearance. Body of live specimens membranous, broadly-oval, $1.5-1.6 \mathrm{~mm}$ long and 0.5-0.6 mm wide, dark yellow to brown in colour. Anterior wing-buds extending to about level with metathoracic coxa. Penial lobe broadly rounded.

Mounted specimen: body 1527 (1450-1630) $\mu \mathrm{m}$ long and 691 (650-760) $\mu \mathrm{m}$ wide. Head, thorax and abdomen not distinctly separated from each other. Segmentation of abdominal segments faintly distinguishable. Body setae fine and blunt or setaceous.

Margin. Anterior wing-buds 426 (395-455) $\mu \mathrm{m}$ long and 171 (160-190) $\mu \mathrm{m}$ wide; posterior wing-buds absent. Setae distributed as follows: on the head and thorax a single row of about 10 setae (a), each 11.8 (7.5-15.0) $\mu \mathrm{m}$ long. On the abdomen two rows of setae: marginal (b) and submarginal (c), each consisting of 8 setae arranged segmentally on abdominal segments I-VIII; marginal setae 15.5 (10-20) $\mu \mathrm{m}$ long, submarginal setae 18.6 (12.5-22.5) $\mu \mathrm{m}$ long. Occasionally $1-2$ setae missing.

Dorsum. Setae distributed as follows: about 5 head setae, located medially, each 13.2 (7.5-25) $\mu \mathrm{m}$ long; thoracic and abdominal setae arranged segmentally in 2 longitudinal rows: mesolateral (d) and submedial (e), each consisting of 10-11 setae: 2-3 on thorax and 8 on abdominal segments I-VIII; mesolateral setae 10.93 (7.5-15) $\mu \mathrm{m}$ long, submedial setae 9.4 (7.5-12.5) $\mu \mathrm{m}$ long, not including very short setae (about $2.5 \mu \mathrm{m}$ long) on abdominal segment VIII. Occasionally 1-2 setae missing. Anal lobes slightly sclerotized, each lobe with apical setae (f) 54 (50-58) $\mu \mathrm{m}$ long. Medial penial lobe sclerotized, 105 (100-115) $\mu \mathrm{m}$ long and 115 (107-125) $\mu \mathrm{m}$ wide, with 1 pair of setae on two body halves, each seta 9 (713) $\mu \mathrm{m}$ long.

Venter. Eyes absent. Antennae 9-segmented, total length 254 (240-270) $\mu \mathrm{m}$, width at base 75.6 (65-95) $\mu \mathrm{m}$. Spiracles subequal in size, 59 (57-63) $\mu \mathrm{m}$ long with peritreme 20.7 (20-23) in diameter, usually without pores, but occasionally the anterior spiracle with 1 trilocular or quinquelocular pore, $5 \mu \mathrm{m}$ in diameter. Legs poorly developed, 3 -segmented; overall lengths: prothoracic 225 (210-220) $\mu \mathrm{m}$, mesothoracic 238 (230-250) $\mu \mathrm{m}$, metathoracic 226 (210-240) $\mu \mathrm{m}$. Head setae of 5 located medially, each 12 (7.5-17.5) $\mu \mathrm{m}$ long; thoracic setae in most cases located near anterior spiracles and mesad of coxae, each 6.5 (5.0 -12.5) $\mu \mathrm{m}$ long; abdominal setae on segments II-VII arranged segmentally in 3-4 longitudinal rows: submarginal (g), mesolateral (incomplete) (h), submedial (i) and medial (j) rows; submarginal setae 9.4 (5-15) $\mu \mathrm{m}$ long, mesolateral, submedial and medial setae similar in size to each other,12.4 (5-22.5) $\mu \mathrm{m}$ long. Microspines (k) numerous, present on abdominal segments and on thorax. 


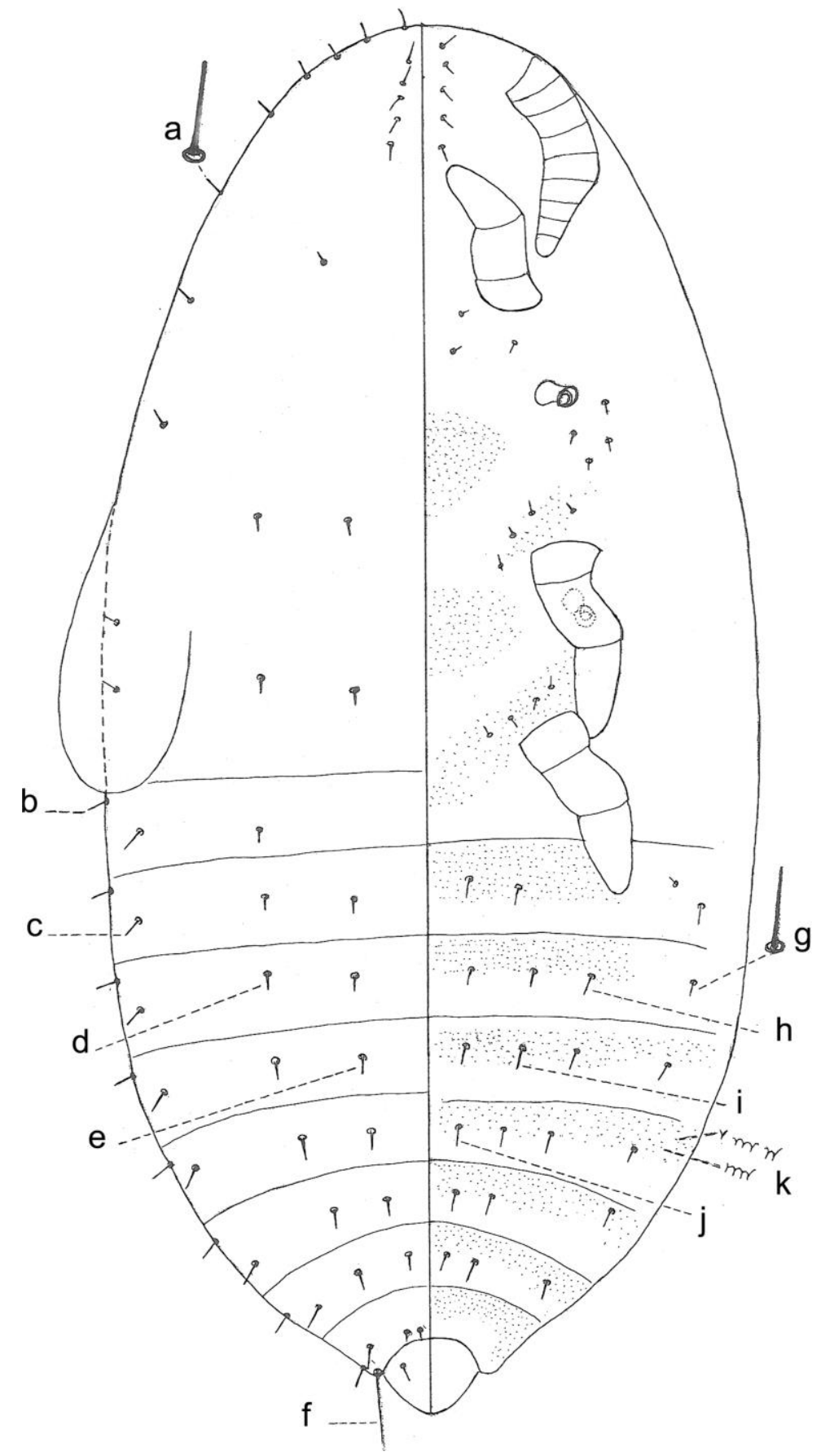

Fig. 2. Third instar male (prepupa) of Kermes quercus; a-k - explanations in the text. 


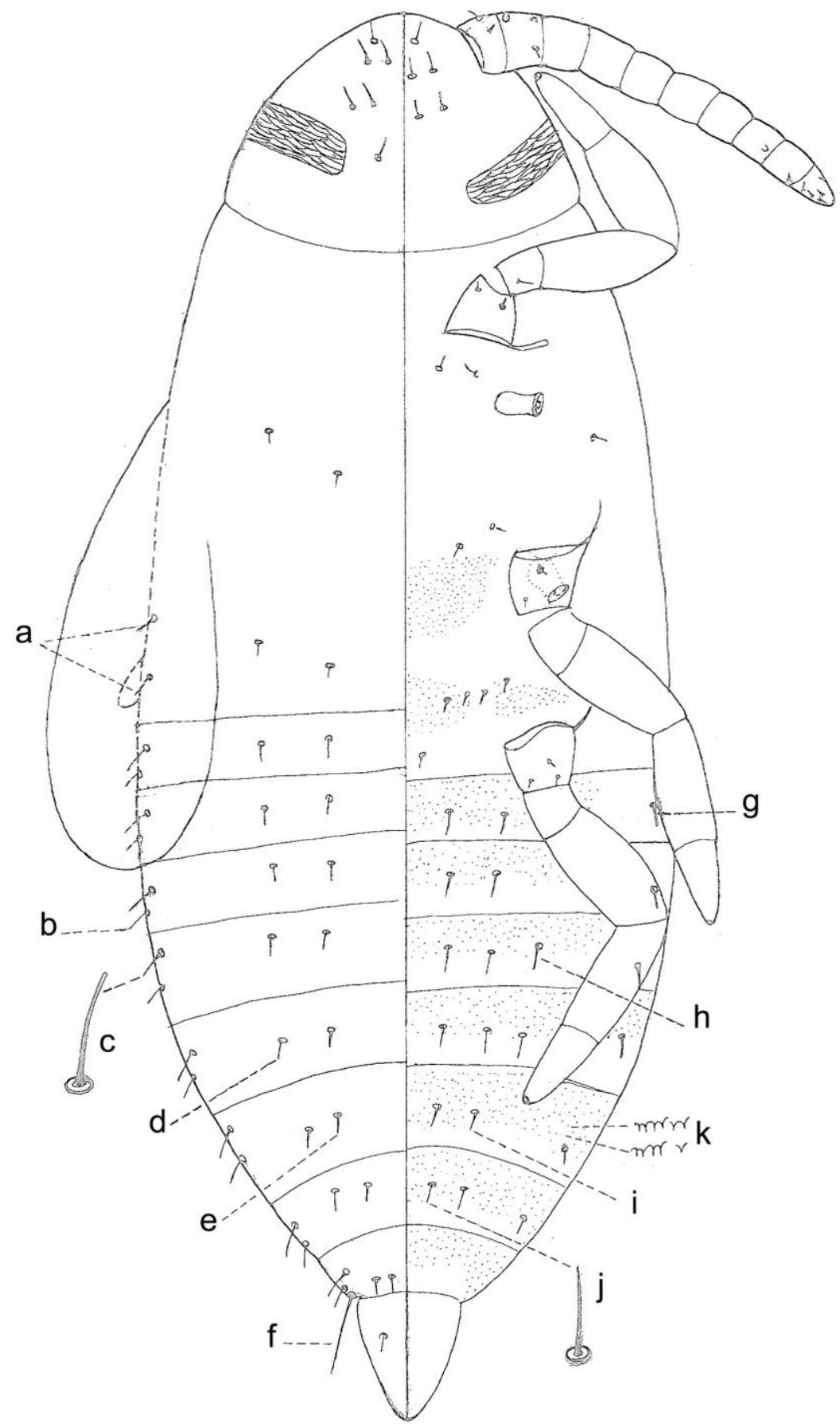

Fig. 3. Fourth instar male (pupa) of Kermes quercus; a-k - explanations in the text. 


\section{Fourth instar male (pupa)}

(Fig. 3)

General appearance. Body of living specimens membranous, elongate-oval, 1.6-1.7 $\mathrm{mm}$ long and $0.5 \mathrm{~mm}$ wide, brown in colour. Anterior wing-buds extending laterally past coxa of metathoracic legs. Penial lobe triangular.

Mounted specimen: body 1644 (1500-1810) $\mu \mathrm{m}$ long and 609 (520-670) $\mu \mathrm{m}$ wide. Head 250 (220-270) $\mu \mathrm{m}$ long and 364 (335-395) $\mu \mathrm{m}$ wide, slightly separated from thorax. Thorax not clearly separated from abdomen. Segmentation of abdomen faintly distinguishable. Body setae fine and blunt or setaceous.

Margin. Fore-wings 604 (590-620) $\mu \mathrm{m}$ long and 196 (180-225) $\mu \mathrm{m}$ wide; hind-wings about $60-80 \mu \mathrm{m}$ long and 40-50 $\mu \mathrm{m}$ wide. Setae distributed as follows: two setae on metathorax in a single row (a), two rows of setae on abdomen: marginal (b) and submarginal (c), arranged segmentally on segments I-VIII; marginal setae 15 (12.5-20) $\mu \mathrm{m}$ long, submarginal setae 23 (17.5-27.5) $\mu \mathrm{m}$ long.

Dorsum. Eyes absent. Ocular sclerite present, reticulated. Setae distributed as follows: about 6 head setae, located medially, each 15.5 (12.5-22.5) $\mu \mathrm{m}$ long; thoracic and abdominal setae arranged segmentally in 2 longitudinal rows: mesolateral (d) and submedial (e), each consisting of 10 setae: 2 on thorax and 8 on abdominal segments I-VIII; thoracic setae 5-7 $\mu \mathrm{m}$ long, abdominal mesolateral setae 12 (8.5-15) $\mu \mathrm{m}$ long and abdominal submedial setae 9.5 (7.5-16) $\mu \mathrm{m}$ long. Occasionally 1-2 setae missing; anal lobes slightly sclerotized, each lobe with 1 apical seta (f) 60 (38-78) $\mu \mathrm{m}$ long. Medial penial lobe sclerotized, 144 (125-157) $\mu \mathrm{m}$ long and 135 (110-152.5) $\mu \mathrm{m}$ wide, with 1 pair of setae on two body halves, each seta 15 (12.5-17.5) $\mu \mathrm{m}$ long.

Venter. Ocular sclerite similar to that on dorsum. Antennae 10 segmented, total length 500 (480-520) $\mu \mathrm{m}$, width at base 83.5 (75-90) $\mu \mathrm{m}$; setal primordia usually visible, especially on segments I, II, IX and X. Spiracles subequal in size, 65 (62-67.5) $\mu \mathrm{m}$ long with peritreme $21.6(17.5-27.5) \mu \mathrm{m}$ in diameter, without pores. Legs well-developed, 5segmented; distal end of tarsus with small triangular claw; measurements presented in Table 1.

Table 1. Dimensions (in $\mu \mathrm{m}$ ) of legs in fourth instar male (pupa) of Kermes quercus.

\begin{tabular}{|l|r|r|r|}
\hline \multirow{2}{*}{ Part of leg } & \multicolumn{3}{|c|}{ Lenght } \\
\cline { 2 - 4 } & Prothoracic & Mesothoracic & Metathoracic \\
\hline Coxa & $66(60-80)$ & $72(60-80)$ & $76(60-85)$ \\
\hline Trochanter + femur & $178(165-195)$ & $186(175-210)$ & $191(160-205)$ \\
\hline Tibia & $141(120-155)$ & $139(130-150)$ & $146(135-165)$ \\
\hline Tarsus & $98(95-105)$ & $98(90-105)$ & $101(95-110)$ \\
\hline Entire leg & $483(455-515)$ & $495(470-535)$ & $514(470-550)$ \\
\hline
\end{tabular}


Head setae of 3-5 located medially, each 12.5 (10-15) $\mu \mathrm{m}$ long; thoracic setae rather rare, in most cases located mesad of coxae, 5-7 $\mu \mathrm{m}$ long; abdominal setae on segments IIVII, arranged segmentally in 3-4 longitudinal rows: submarginal (g), mesolateral (incomplete) (h), submedial (i) and medial (j) rows; submarginal setae 14 (10-22.5) $\mu \mathrm{m}$ long, mesolateral, submedial and medial setae similar in size, 18 (10-27,5) $\mu \mathrm{m}$ long. Microspines (k) numerous, present on all abdominal segments and on thorax.

\section{Notes}

The prepupal stage begins the transformation of the body into a form quite different from that occurring in the female. In the prepupa of $K$. quercus the body is broadly oval, membranous, with indistinct segmentation; the antennae have 9 poorly defined segments, the legs are somewhat lobe-like, 3-segmented; the anterior wing-buds extend roughly as far as the base of the metathoracic legs; the medial penial lobe is broadly rounded. In the pupa of $K$. quercus the body remains membranous but is more slender and the appendages are more strongly developed; the antennae are 10-segmented with setal primordia; the legs are 5 -segmented with small triangular claws; the anterior wing-buds extend laterally past the coxa of the metathoracic legs; the medial penial lobe longer, triangular.

Pupal instars from the genus Kermes BoITARD, 1828 are not well known. Among the Nearctic species, the pupal instars of Kermes kingii COCKERELL, 1898 (placed in a new genus Allokermes by Bullington \& KosZTARAB 1985) were described from Virginia by HAMON et al. (1976). Among the Palaearctic Kermes, SPODEK \& BEN-DOV (2014) described the pupal instars of 5 species from Israel: K. echinatus BALACHOWSKY, 1953, K. greeni BODENHEIMER, 1931, K. hermonensis SPODEK \& BEN-DOv, 2014, K. nahalali BODENHEIMER, 1931 and K. spatulatus BALACHOWSKY, 1953.

\section{REFERENCES}

Bullington S.W., KoszTARAB M. 1985. Studies on the morphology and systematics of scale insects, no. 12.I. Revision of the family Kermesidae (Homoptera) in the Nearctic region based on adult and third instar females. Bulletin of the Virginia Polytechnic Institute and State University Agricultural Experiment Station 85(11): 1-118.

Hamon A.B., Lambdin P.L., Kosztarab M. 1976. Studies on the morphology and systematics of scale insects, no. 8. Life history and morphology of Kermes kingii in Virginia (Homoptera: Coccoidea: Kermesidae). Bulletin of the Virginia Polytechnic Institute and State University Research Division 111: 1-31.

Koteja J., ŻAK-OgaZA B. 1972. Morphology and taxonomy of the male Kermes quercus (L.) (Homoptera, Coccoidea). Acta Zoologica Cracoviensia 17(8): 193-215.

NASONOV N.V. 1910. On the metamorphosis of Kermes quercus (LiNN.). Bulletin de l'Académie Impériale des Sciences de St.-Pétersbourg (6e serié) 4(1): 47-60. (in Russian) 
PodsiadŁo E. 2005a. Morphological peculiarities in adult females of Kermes quercus (LinNaEus) (Hemiptera: Coccinea: Kermesidae). Polskie Pismo Entomologiczne 74(1): 43-46.

Podsiadıo E. 2005b. Morphology of the first instar of Kermes quercus (LinNaEus) (Hemiptera: Coccinea: Kermesidae). Polskie Pismo Entomologiczne 74(1): 47-52.

Podsiadeo E. 2012a. Morphology of second instar nymphs of Kermes quercus (LinNaeus) (Hemiptera: Kermesidae). Polish Journal of Entomology 81(1): 35-42.

PodsiadŁo E. 2012b. Changes in the body proportions of the first-instar nymphs of Kermes quercus (LiNNAEUs 1758) (Hemiptera: Kermesidae) during growth. Aphids and other Hemipterous Insects 18: $5-11$.

PodsiadŁo E. 2013. Life history of Kermes quercus (Linnaeus) (Hemiptera: Kermesidae) in Poland. Polish Journal Entomology 82(3): 151-158.

PodsiadŁo E. 2014. Identification characters of nymphal instars and adult female of Kermes quercus (LinNAeus, 1758) (Hemiptera: Kermesidae). Polish Journal Entomology 83(4): 259-268.

SAAKYAN-BARANOva A.A., MuZafarov S.S. 1972. Structure, biology and interrelationships of northern gall-coccid Kermococcus quercus L. (Homoptera, Kermococcidae) and its parasites (Hymenoptera, Chalcidoidea). Entomologicheskoe Obozrenye 51(3): 498-519. (in Russian)

SPODEK M., BEN-Dov Y. 2014. A taxonomic revision of the Kermesidae (Hemiptera: Coccoidea) in Israel, with a description of a new species. Zootaxa 3781(1): 1-99.

Received: 19 June 2015

Accepted: 18 July 2015 